\title{
The Properties of ZnO Deposits Electroplated on an ITO Glass Substrate with Direct- and Pulse Currents
}

\author{
Ching An Huang, Chin Huo Chuang, Fu Yung Hsu, and Kong Chen Li
}

\begin{abstract}
The microstructures and optical properties of the $\mathrm{ZnO}$ deposits were investigated, which were electroplated with direct- and pulse-currents on an ITO-glass in a zinc-nitrate based electrolyte. The surface morphologies of the electroplated ZnO deposits were examined with field emission scanning electron microscope, and their microstructures were detected with X-ray diffractrometer. Meanwhile the transparencies of ZnO-deposited ITO-glass specimens were evaluated. Experimental results show that the surface morphologies, microstructures, and optical properties of the $\mathrm{ZnO}$ deposits depend strongly on the plating bath temperature and current density. An amorphous structure of $\mathrm{ZnO}$ deposit was achieved when it was electroplated at a bath temperature of $30^{\circ} \mathrm{C}$; while a crystalline $\mathrm{ZnO}$ deposit with hexagonal grains was observed at a plating temperature of $60 \circ \mathrm{C}$. The crystalline $\mathrm{ZnO}$ deposits with a preferred orientation of (101) were obtained by using different plating current densities. With the same coating thickness, the $\mathrm{ZnO}$ deposits prepared at $30^{\circ} \mathrm{C}$ revealed higher transparencies than those prepared at $60^{\circ} \mathrm{C}$. Moreover, the transparency of ITO glass can be markedly improved at a wavelength higher than $500 \mathrm{~nm}$ when it was coated a thin $\mathrm{ZnO}$ layer by using pulse-current plating at $30 \circ \mathrm{C}$.
\end{abstract}

Index Terms-Electroplating, transparency, $\mathrm{ZnO}$ deposit.

\section{INTRODUCTION}

Based on the variety of optoelectronic devices, transparent conductive oxides (TCOs) are being improved to meet the required properties of devices. Zinc oxide, an n-type semiconductor with a direct energy bandgap of $3.4 \mathrm{eV}$, and its related materials are being applied in optoelectronic devices, such as light emitting devices, solar cell, and chemical sensors, etc. [1], owing to its particular electrical and optical properties. Until now, the gas phase techniques, such as sputtering, MOCVD, and pulse laser deposition are the main methods to prepare TOCs. However, preparation of $\mathrm{ZnO}$ deposit with electroplating method has been much more attracted because of low cost and convenience for mass production.

Electrodepostion for preparing $\mathrm{ZnO}$ deposit was developed by Izaki et al. [2] and Lincot [3]. Generally, ZnO deposits were prepared by potentiostatic electrodeposition [4]-[8]. Pulsed current electroplating is widely used in electroplating industry, because it has several advantages compared with both potentiostatic and galvanostatic plating techniques. The application of pulse-current electroplating

Manuscript received June 29, 2015; revised October 16, 2015.

Ching An Huang, Chin Huo Chuang and Kong Chen Li are with the Department of Mechanical Engineering, Chang Gung University, Taoyuan 333, Taiwan (e-mail: gfehu@mail.cgu.edu.tw).

Fu Yung Hsu is with the Department of Materials Engineering, Ming Chi University of Technology, New Taipei 243, Taiwan. can easily increase the density of deposited nuclei to obtain a fine-grain deposit. Moreover, the defects in the deposit, such as pinholes, cracks, and voids etc., could be reduced [9].

Nomura et al. [10], [11] reported that the preferred orientation of $\mathrm{ZnO}$ deposits was changed in an order of (0002), (1011), and (1010) with lengthening the pulse period, (Ton+Toff). In addition, the $\mathrm{ZnO}$ deposit with a high transparency above 95\% was obtained at a wavelength of 600 $\mathrm{nm}$. Lee et al. [12] reported that the adsorbed hydroxide ion reduced from dissolved oxygen to form $\mathrm{ZnO}$ is affected by the cathodic time of pulse-potential electrodeposition. Izaki [8] first proposed the electrodeposition mechanism of $\mathrm{ZnO}$ and depicted that the final reaction, dehydration of zinc hydroxide, occurs only when the plating temperature is higher than $60^{\circ} \mathrm{C}$. He found that electrocrystallization of $\mathrm{ZnO}$ is significantly affected by bath temperatures. Goux et al. [13] pointed out the effect of plating temperature on the Zn-Cl-H2O system by using potential-pH, solubility, and species repartition diagrams. They found that the absence of continuous film was found at a bath temperature below $34^{\circ} \mathrm{C}$. Nucleation and film growth of $\mathrm{ZnO}$ were observed at a temperature above $34^{\circ} \mathrm{C}$ and the optimum transparency of $\mathrm{ZnO}$ was obtained at plating temperature of $40^{\circ} \mathrm{C}$.

In this study, $\mathrm{ZnO}$ deposits were prepared with direct-and pulse-current electroplating methods. In pulse-current electroplating, three different Ton and Toff ratios of $1: 1,2: 1$, and 3: 1 were conducted. Two bath temperatures of 30 and $60 \mathrm{oC}$ were set for electrodeposition of $\mathrm{ZnO}$. All $\mathrm{ZnO}$ deposits were electroplated on ITO-coated glass. After electroplating, the surface morphologies and microstructures of $\mathrm{ZnO}$ deposits were characterized with field emission scanning electron microscope (FESEM) and X-ray diffratometer (XRD). Meanwhile, the optical and electrical properties of $\mathrm{ZnO}$ deposits on ITO-coated glass were analyzed and discussed.

\section{EXPERIMENTAL PROCEDURE}

The ITO-coated glass was used as the substrate for $\mathrm{ZnO}$ electroplating in this study. Prior to electroplating, as-received ITO-coated glass was ultrasonically cleaned in acetone for $2 \mathrm{~min}$ and then in ethanol for $2 \mathrm{~min}$. An electrochemical three-electrode cell was used for electrodeposition of $\mathrm{ZnO}$ with direct and pulse currents. An ITO-coated glass and a pure zinc plate (99.98\%) parallel to etch other were used as the working and counter electrodes, respectively. An $\mathrm{Ag} / \mathrm{AgCl}$ electrode in the saturated $\mathrm{KCl}$ solution was used as the reference electrode. All electrochemical experiments were performed with potentiostat/galvanostate (EG\&G Model 263A). A piece of 
copper foil in ring shape was tightly connected with the ITO-coated glass to ensure a uniform electrical field during electroplating. The ITO-coated glass and the copper ring were then strongly clipped between a PE (Polyethylene) cover and a circle plate. The main chemical composition of electroplating bath was $0.1 \mathrm{M}$ zinc nitrate (Alfa Aesar, $99.998 \%$ ). The $\mathrm{ZnO}$ deposits were electroplated with plating current densities of 0.05 and $1 \mathrm{mAcm}-2$ at bath temperatures of 30 and $60^{\circ} \mathrm{C}$, respectively. In each pulse cycle of pulse-current electroplating, cathodic current was applied during pulse on (Ton) and nil current during pulse off (Toff). The cathodic current densities applied during Ton in each cycle at bath temperatures of $30^{\circ} \mathrm{C}$ and $60^{\circ} \mathrm{C}$.

After electroplating, the $\mathrm{ZnO}$-deposited samples were ultrasonically cleaned in acetone for $3 \mathrm{~min}$, immersed in ethanol alcohol for 2 min, dried with cold blaster and then prepared for structure and surface morphology study. The microstructures of $\mathrm{ZnO}$-deposited samples prepared with different electroplating parameters were characterized with X-ray diffractrometer (XRD, Philip X'pert) by using thin film mode. Filtered $\mathrm{Cu}-\mathrm{K} \alpha$ radiation with an accelerating voltage of $40 \mathrm{kV}$ and current of $30 \mathrm{~mA}$ was used for structure diffraction. The spectra were recorded in the $2 \theta$ interval between $20^{\circ}$ and $80^{\circ}$ with a scan rate of $0.05^{\circ}$ min- 1 . Parallel beams are employed for thin film analyses with an incident angel of $0.3^{\circ}$. The surface morphologies of $\mathrm{ZnO}$-deposited samples were observed with field-emission electron microscope (FESEM, Hitachi Model S-4700) integrated with an energy-dispersive x-ray spectrometer (EDS; EDAX company, series No: 8318-46390 ME) for chemical composition analysis.

\section{RESULTS AND DISCUSSION}

\section{A. Microstructural Study with XRD}

The XRD patterns of ZnO-deposited samples electroplated at bath temperatures of 30 and $60{ }^{\circ} \mathrm{C}$ are shown in Fig. 1 . The results show that only the peaks of ITO film with a preferred orientation of (222) were detected from the $\mathrm{ZnO}$-deposited samples prepared at $30{ }^{\circ} \mathrm{C}$. The Zinc hydroxide does not appear in XRD pattern, although it would be developed during electroplating through incorporation of a hydroxide phase in the deposit [14]. It is probably that zinc oxide and zinc hydroxide are amorphous or their quantities are too low to be detected. On the other hand, obvious $\mathrm{ZnO}$-peaks of (100), (002), and (101), which correspond to the würtzite structure of $\mathrm{ZnO}$, were detected from the $\mathrm{ZnO}$-deposited samples prepared at $60^{\circ} \mathrm{C}$. They have a preferred orientation of (101). This result is disagreement with the $\mathrm{ZnO}$ deposit prepared with rf sputtering, with which the $\mathrm{ZnO}$ deposit has a preferred orientation of (002) [15]. Yoshida [15] reported that the (002) plane of $\mathrm{ZnO}$ is the closest packed and the most stable plane in contact with the solution. According to our experimental results, the growth orientation of $\mathrm{ZnO}$ deposit could be affected by electroplating current density. These results are similar to those reported by Izaki et al. [2], [16]. They reported that both (002)- and (101)-diffracted peaks could be observed in XRD patterns with whatever the zinc nitrate concentration and electroplating current density.

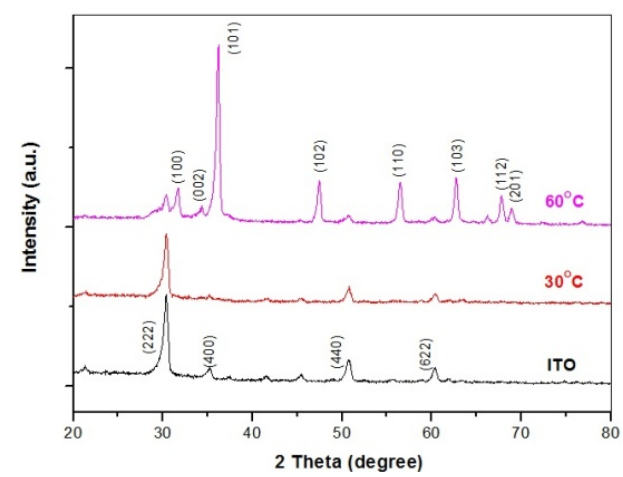

Fig. 1. XRD spectra of $\mathrm{ZnO}$ films electroplated on ITO-coated glass at bath temperatures of $30^{\circ} \mathrm{C}$ and $60^{\circ} \mathrm{C}$ for $1800 \mathrm{~s}$.

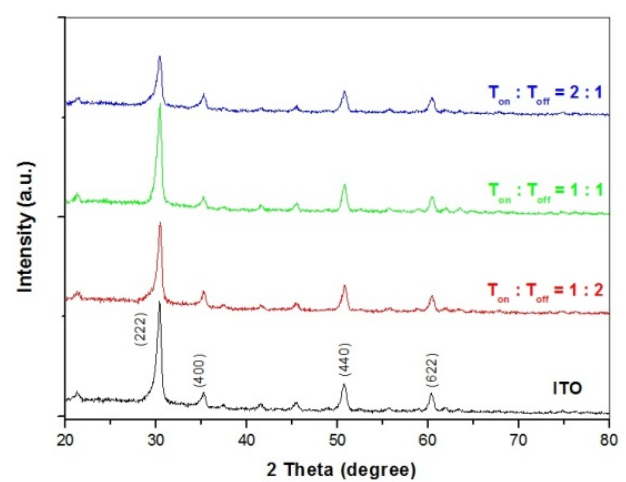

(a)



(b)

Fig. 2. XRD spectra of ZnO films electroplated on ITO-glass with different duty cycles and pulsed current densities of 0.05 and $1 \mathrm{~mA} / \mathrm{cm} 2$ at bath temperatures of (a) $30^{\circ} \mathrm{C}$ and (b) $60^{\circ} \mathrm{C}$.

The XRD patterns of the ZnO-deposited samples electroplated with pulsed currents by using different pulse ratios are shown in Fig. 2. As shown in Fig. 2(a), no peaks corresponding to crystalline $\mathrm{ZnO}$ were observed except the ITO peaks with a preferred orientation of (222) after electroplating at $30 \circ \mathrm{C}$. This could be resulted from a very thin or even amorphous $\mathrm{ZnO}$ which can't provide enough diffracted intensity. On the other hand, crystalline $\mathrm{ZnO}$ deposits were achieved after electroplating at $60{ }^{\circ} \mathrm{C}$. This can be recognized from their XRD patterns shown Fig. 2(b) in which these $\mathrm{ZnO}$ deposits have a hexagonal Würtztite structure with fitting JCPDS files [17]. These three $\mathrm{ZnO}$ deposits have a preferred orientation of (101) and its intensity increases with increasing Ton period. Generally, $\mathrm{ZnO}$ grains grow with c-axis, i.e., (002) direction, perpendicular to substrate due to (002) plane has the lowest surface energy. Nomura et al. [10], [11] reported that the orientation of electrodeposited $\mathrm{ZnO}$ would be affected by pulse-electroplating parameters. However, this effect was not found in this study. 


\section{B. Surface Morphologies}

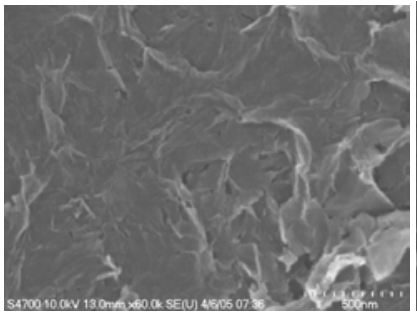

(a)

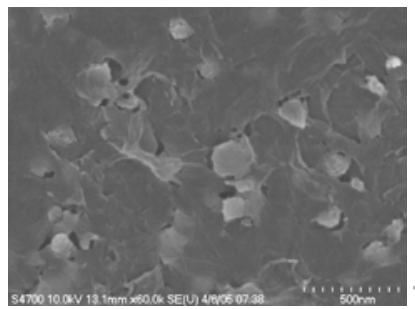

(c)



(b)

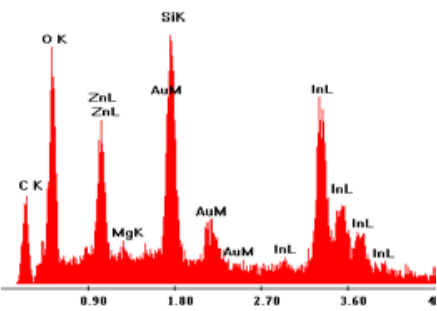

(d)
Fig. 3. Surface morphologies of ZnO films electroplated on ITO-glass with a pulse-current density of $0.05 \mathrm{~mA} / \mathrm{cm} 2$ at $300 \mathrm{C}$ with the Ton: Toff ratios of (a) $1: 2$, (b) $1: 1$, and (c) $2: 1$; (d) EDS spectrum of the ZnO film shown in (a).

Fig. 3 shows the surface morphologies of the $\mathrm{ZnO}$ deposits electroplated at $30^{\circ} \mathrm{C}$ with direct and pulse currents. The well-covered $\mathrm{ZnO}$ deposits on ITO-glasses were observed after all plating conditions. As shown in Fig. 4, a ZnO deposit with wavelike surface was developed after electroplating at $30 \circ \mathrm{C}$. With increasing the ratios of Ton and Toff higher than $1: 1$, some crystalline $\mathrm{ZnO}$ particles in a size of about 100-200 $\mathrm{nm}$ were detected in the $\mathrm{ZnO}$ deposit. From the measurement with $\alpha$-step profilometer, the thickness of $\mathrm{ZnO}$ deposit is estimated to be $150 \mathrm{~nm}$. Owing to having wavelike morphology, a relatively high roughness of $\mathrm{ZnO}$ deposit can be expected after pulse-current electroplating. As Ton increased, a smooth film with few tiny voids around particles were observed as shown in Fig. 3(b). Fig. 3(c) shows the surface morphology of $\mathrm{ZnO}$ deposits prepared with pulse ratio of 2: 1 . This deposit was formed with some particles as a combination of the previous two cases. The crystalline particles shown here are larger than those in Fig. 3(b). This indicates that a high ratio of Ton and Toff is helpful for the formation of crystalline $\mathrm{ZnO}$ particles. The surface morphologies of pulse-current prepared $\mathrm{ZnO}$ deposits are similar to those prepared with direct current plating. Surface morphologies of the ZnOs prepared with direct- and pulse-current methods with different pulse ratios at a bath temperature of $60^{\circ} \mathrm{C}$ are shown in Fig. 4(a)-Fig. 4(d). From EDS analysis, the chemical composition of the $\mathrm{ZnO}$ deposit prepared with direct- or pulse-current is almost identical. One of EDS-spectra is shown in Fig. 4(e) in which only Zn and O elements were detected. As shown in Fig. 4(a) the $\mathrm{ZnO}$ deposits prepared with direct current reveal a homogeneous structure composed of columnar grains without pores and voids, and the thickness is about $1000 \mathrm{~nm}$. For $\mathrm{ZnO}$ deposits prepared with pulse current, the surfaces were well-covered by many ZnO grains with hexagonal structure. No pores or tiny voids can be detected from the $\mathrm{ZnO}$ surfaces. The $\mathrm{ZnO}$ deposit shown in Fig. 4(b) was composed of the smaller $\mathrm{ZnO}$ grains with lower roughness compared with the other two conditions as shown in Figs. 4(c) and Figs. 4(d) but the orientations are a little different. Roughness is a little higher for the $\mathrm{ZnO}$ deposit prepared with a pulse ratio of $2: 1$ than those prepared with pulse ratios of $1: 1$ and 1:2.As shown in Fig. 4(a)-Fig. 4(e) the grain size of $\mathrm{ZnO}$ deposit prepared with direct current was obviously larger than the others prepared with pulse current. It implies that the $\mathrm{ZnO}$-deposit structure could be affected by using pulsed current electroplating; moreover, its surface roughness can be altered by adjusting the ratio of Ton and Toff. Therefore, we could expect the different optical properties from these $\mathrm{ZnO}$ deposits prepared with direct- and pulse-current methods.

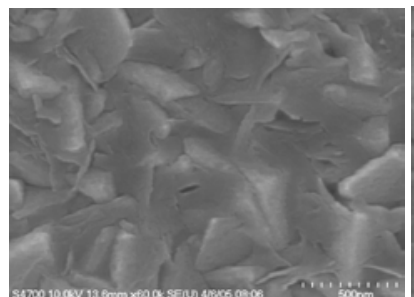

(a)

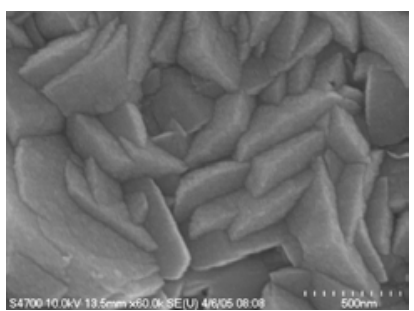

(c)

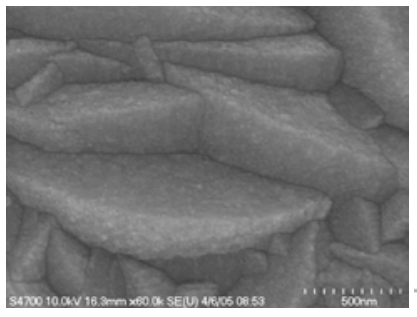

(e)



(b)

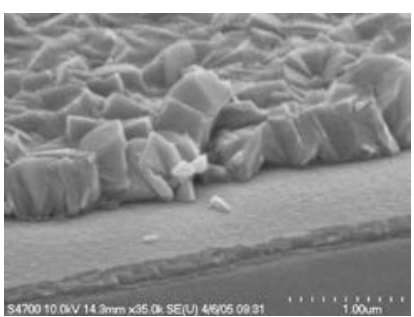

(d)

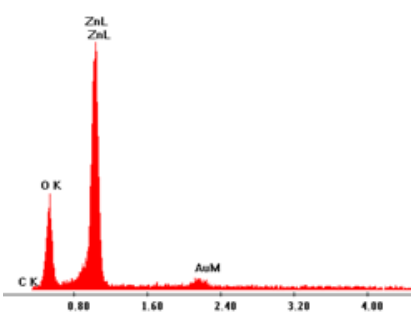

(f)
Fig. 4. Surface micrographs of $\mathrm{ZnO}$ films prepared with (a) Direct current, and pulsed current at 60OC with the Ton : Toff ratios of (b) $1: 2$, (c) $1: 1$, and (d) $2: 1$; (e) Cross-sectional view of (d), and (f) EDS spectrum of the $\mathrm{ZnO}$ film shown in (c).

\section{Optical Properties}

Fig. 5 shows the optical transmittance spectra of the $\mathrm{ZnO}$-coated samples prepared at bath temperatures of 30 and $60{ }^{\circ} \mathrm{C}$ as well as with plating current densities of 0.05 and 1 mAcm-2. The transparency of a $\mathrm{ZnO}$-deposited sample was measured by taking air as background. Comparing with the transparency of the bare ITO glasses, the $\mathrm{ZnO}$-deposited ITO-glass exhibited relatively low transparency at a wavelength ranging from 400 to $550 \mathrm{~nm}$, but the transparencies steadily increased through whole visible wavelength range. That is, relatively high absorption of $\mathrm{ZnO}$-deposited samples was detected in the short wavelength range. The $\mathrm{ZnO}$ deposits prepared at $60^{\circ} \mathrm{C}$ have the obviously lower transparency that those prepared at $30^{\circ} \mathrm{C}$. Their appearances visually present milk-white color. The milk-white color indicates that the reflectance is rather strong on surface, because of having relatively high surface roughness. Normally, the transparency of thin films is strongly related to its surface condition. A better transparency of a thin film could be obtained when it has a low surface roughness and, moreover, a defect-free surface. 
In this study, the $\mathrm{ZnO}$ deposits were prepared at $60{ }^{\circ} \mathrm{C}$ for a long deposition period which may cause larger crystalline grains and rough surface decreasing their transparency.



Fig. 5. Optical transmittance spectra of the $\mathrm{ZnO}$-deposited ITO films electroplated at three bath temperatures of 30,45 and $60^{\circ} \mathrm{C}$ with current densities of $0.05,0.1$, and $1 \mathrm{~mA} / \mathrm{cm} 2$ for $1800 \mathrm{sec}$, respectively.

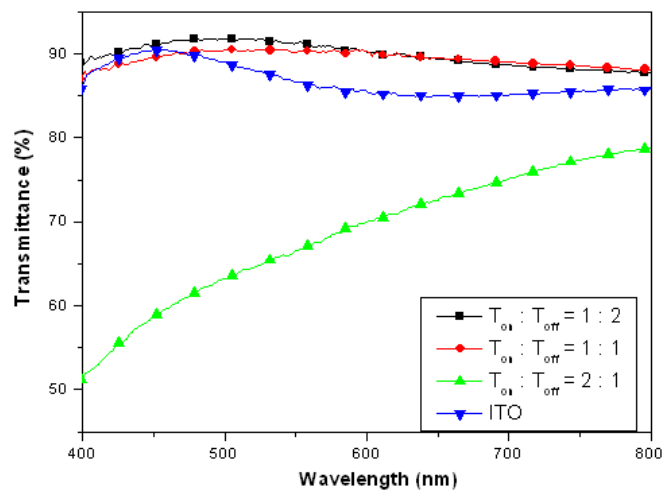

(a)

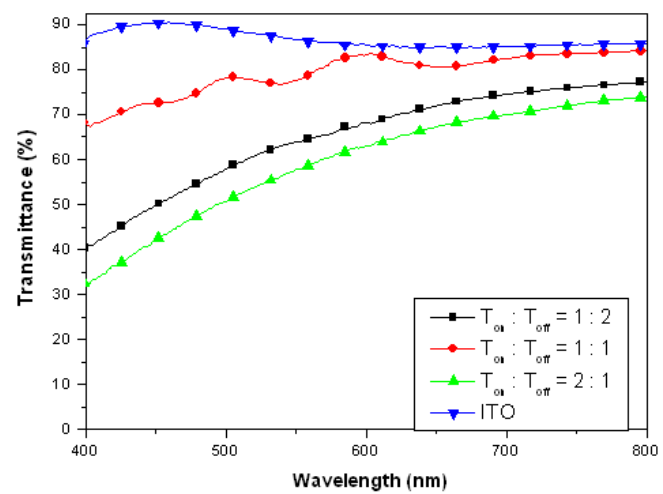

(b)

Fig. 6. Optical transmittance spectra of the $\mathrm{ZnO}$-deposited ITO films prepared with different duty cycles and pulsed current densities of 0.05 and 1 $\mathrm{mA} / \mathrm{cm} 2$ at bath temperatures of (a) $30^{\circ} \mathrm{C}$ and (b) $60^{\circ} \mathrm{C}$.

Optical transmittance spectra of the $\mathrm{ZnO}$-coated ITO films electroplated with pulse-current method are shown in Fig. 6. In Fig. 6(a), the $\mathrm{ZnO}$ deposits prepared with pulse ratios of 1 : 2 and 1: 1 at 300C exhibit better transparencies than that of the bare ITO film at a wavelength over $500 \mathrm{~nm}$. This effect could be used to compensate the loss of transparency of ITO films at wavelength over $500 \mathrm{~nm}$. The $\mathrm{ZnO}$-deposited ITO-glasses prepared at $60{ }^{\circ} \mathrm{C}$ have lower transparencies than that of ITO glass through whole visible wavelength range as shown in Fig. 6(b). This could be possibly attributed to $\mathrm{ZnO}$-grain boundaries developed from this plating condition. It is believed that scattering takes place when light transmits across grain boundaries. Therefore, the more grain boundaries have, and the lower transparency could be. The same results can be seen from Fig. 5. Transparencies of $\mathrm{ZnO}$-deposited ITO glasses were gradually increased through whole visible wavelength range. The transparency of the ZnO-deposited ITO glasses prepared with pulse ratio of 1 : 1 was about $10 \%$ higher than those with the other two pulse ratios.

\section{CONCLUSION}

The structural and optical properties of $\mathrm{ZnO}$ deposits were studied which were electroplated on an ITO-glass at bath temperatures of $30{ }^{\circ} \mathrm{C}$ and $60{ }^{\circ} \mathrm{C}$ with direct- and pulse-currents. The $\mathrm{ZnO}$ deposits prepared at $30{ }^{\circ} \mathrm{C}$ have low crystallinity. Electroplating at $60{ }^{\circ} \mathrm{C}$, the $\mathrm{ZnO}$ deposits revealed a crystalline würtztite structure with a preferred orientation of (101) which is different from rf-spattered $\mathrm{ZnO}$ deposits with a preferred orientation of (002).

The wavelike appearances with smooth and partially crystallized granular $\mathrm{ZnO}$ particles were found when $\mathrm{ZnO}$ deposits were prepared at $30^{\circ} \mathrm{C}$. The lowest surface roughness of $\mathrm{ZnO}$ deposit was detected by using a pulse ratio of $1: 1$. The $60^{\circ} \mathrm{C}$-prepared $\mathrm{ZnO}$ deposits revealed a homogeneous structure composed of hexagonal grains without pores and voids. The pulse-current method effectively altered the grain size and surface roughness of the $\mathrm{ZnO}$ deposit prepared at $60^{\circ} \mathrm{C}$ by adjusting the ratio of Ton and Toff. In terms of optical properties, the $30^{\circ} \mathrm{C}$-prepared $\mathrm{ZnO}$ deposits revealed higher transparencies than those of the $60{ }^{\circ} \mathrm{C}$-prepared $\mathrm{ZnO}$ deposits. The pulse-prepared $\mathrm{ZnO}$ deposits at $30^{\circ} \mathrm{C}$ exhibited the superior transparencies to that of the bare ITO film at wavelength over $500 \mathrm{~nm}$. By taking ITO film as background, the $30^{\circ} \mathrm{C}$-prepared $\mathrm{ZnO}$ deposits exhibited the excellent transparencies over $100 \%$ through whole visible wavelength range.

\section{REFERENCES}

[1] C. J. Gawlak and C. P. Aita, "Stress relief of basal orientation zinc oxide thin films by isothermal annealing,” J. Vac. Sci. Technol. A, vol. 1, pp. 415-418, 1983.

[2] M. Izaki and T. Omi, "Transparent zinc oxide films prepared by electrochemical reaction,” Appl. Phys. Lett., vol. 68, pp. 2439-2440, 1996.

[3] S. Peulon and D. Lincot, "Cathodic electrodeposition from aqueous solution of dense or open-structured zinc oxide films,” Adv. Mater., vol. 8, pp. 166-169, 1996.

[4] M. Izaki, "Preparation of transparent and conductive zinc oxide films by optimization of the two-step electrolysis technique,” J. Electrochem. Soc., vol. 146, pp. 4517-4521, 1999.

[5] T. Pauporté and D. Lincot, "Hydrogen peroxide oxygen precursor for zinc oxide electrodeposition”, J. Electrochem. Soc., vol. 148, pp. 310-314, 2001.

[6] Z. H. Gu, T. Z. Fahidy, R. Hornsey, and A. Nathan, "A study of the electrochemical synthesis of ZnO thin films,” Can. J. Chem., vol. 75, pp. 1439, 1997.

[7] J. Weng et al., "Electrochemical deposition and characterization of wide band semiconductor $\mathrm{ZnO}$ thin film," Thin Solid Films, vol. 478, pp. 25-29, 2005.

[8] M. Izaki and T. Omi, "Electrolyte optimization for cathodic growth of zinc oxide films,” J. Electrochem. Soc., vol. 143, pp. 53-55, 1996.

[9] Handbook of Semiconductor Electrodeposition, First ed., CRC Press, New York, 1996.

[10] K. Nomura, N. Shibata, and M. Maeda, "Preparation of zinc oxide thin films by pulsed current electrolysis,” J. Electrochem. Soc., vol. 149, pp. 76-80, 2002. 
[11] K. Nomura, N. Shibata, and M. Maeda, "Orientation control of zinc oxide films by pulsed current electrolysis," J. Crystal Growth, vol. 235, pp. 224-228, 2002.

[12] J. Lee and Y. Tak, "Electrodeposition of ZnO on ITO electrode by potential modulation method,” Electrochem. Solid-State Lett., vol. 4, pp. 63-65, 2001.

[13] A. Goux, T. Pauporté, J. Chivot, and D. Lincot, “Temperature effects on ZnO electrodeposition," ElectrochimicaActa, vol. 50, pp. 2239-2248, 2005.

[14] A. Jiménez-González and R. Suárez-Parra, "Effect of heat treatment on the properties of $\mathrm{ZnO}$ thin films prepared by successive ion layer adsorption and reaction (SILAR)," J. Crystal Growth, vol. 167, pp. 649-655, 1996.

[15] T. Yoshida, S. Ide, T. Sugiura, and H. Minoura, "Orientation controlled electrodeposition of zinc oxide thin films,” Trans. Mater. Res. Soc. Jpn., vol. 25, pp. 1111-1114, 2000.

[16] M. Izaki and T. Omi, "Characterization of transparent zinc oxide films prepared by electrochemical reaction,” J. Electrochem. Soc., vol. 144, pp. 1949-1952, 1997.

[17] Joint Committee on Powder Diffraction Standard, International Center for Diffraction Data, Swarthmore, PA, 1990, Set 36, no. 1451.

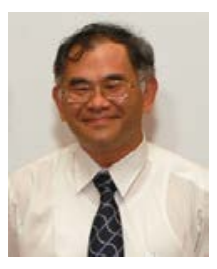

Ching An Huang received the B. S. degree in the Department of Mechanical Engineering from National Chiao Tung University, Taiwan, in 1983 and Dr.-Ing. in the Department of Materials Engineering from Aachen University, Germany, in 1993. In 2006, he joined the faculty of Chang Gung University, Taoyuan, Taiwan, where he is currently a professor in the Department of Mechanical Engineering. His main research interests are microstructure analysis of materials, electro polishing behavior, corrosion engineering, and electroplating technology. Based on his research results, he published over 70 articles in SCI journals, such as Thin Solid Films, Surface and Coatings Technology, ElectrochimicaActa, and Materials Science and Engineer A, Corrosion Science, etc. Moreover, he got about 10 patents from Taiwan, Main China, USA, and Japan.

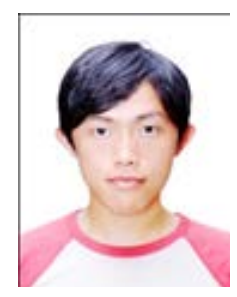

Chin Huo Chuang was born in September 10, 1983 in Taiwan. He earned his bachelor's degree in department of mechanical engineering of Chang Gung University, Taiwan in 2007. He earned his master degree in the Department of Mechanical Engineering of Chang Gung University, Taiwan in 2009. He is currently a $\mathrm{PhD}$ student in the Department of Mechanical Engineering of Chang Gung University in Taoyuan, Taiwan. His study aims on electroplating engineering, microstructure examination, and electrochemistry analysis. His research results have be published in SCI journals, such as Thin Solid Films, Surface and Coatings Technology, and Vacuum.



Fu Yung Hsu was born in Taiwan. He earned his PhD degree in the Department of Materials Engineering of RWTH Aachen University, Germany in 1996. He is currently an associate professor in the Department of Mechanical Engineering of Ming Chi University of Technology in New Taipei City, Taiwan. His research aims on microstructure analysis, electron microscopy, and thin film processing. His research results have be published in SCI journals, such as Corrosion Science, Surface and Coatings Technology, Vacuum, etc. 